\title{
Effects of diet forage source and neutral detergent fiber content on milk production of dairy cattle and methane emissions determined using GreenFeed and respiration chamber techniques
}

\author{
K. J. Hammond, ${ }^{1}$ A. K. Jones, D. J. Humphries, L. A. Crompton, and C. K. Reynolds ${ }^{2}$ \\ Sustainable Agriculture and Food Systems Research Division, Centre for Dairy Research, School of Agriculture, Policy and Development, \\ University of Reading, PO Box 237, Earley Gate, Reading, RG6 6AR, UK
}

\begin{abstract}
Strategies to mitigate greenhouse gas emissions from dairy cattle are unlikely to be adopted if production or profitability is reduced. The primary objective of this study was to examine the effects of high maize silage (MS) versus high grass silage (GS) diets, without or with added neutral detergent fiber (NDF) on milk production and methane emission of dairy cattle, using GreenFeed (GF) or respiration chamber (RC) techniques for methane emission measurements. Experiment 1 was $12 \mathrm{wk}$ in duration with a randomized block continuous design and 40 Holstein cows (74 d in milk) in free-stall housing, assigned to 1 of 4 dietary treatments ( $\mathrm{n}=$ 10 per treatment), according to calving date, parity, and milk yield. Milk production and dry matter intake (DMI) were measured daily, and milk composition measured weekly, with methane yield (g/kg of DMI) estimated using a GF unit (wk 10 to 12). Experiment 2 was a $4 \times 4$ Latin square design with 5 -wk periods and 4 dairy cows (114 $\mathrm{d}$ in milk) fed the same 4 dietary treatments as in experiment 1. Measurements of DMI, milk production, and milk composition occurred in wk 4, and DMI, milk production, and methane yield were measured for $2 \mathrm{~d}$ in RC during wk 5 . Dietary treatments for both experiments were fed as total mixed rations offered ad libitum and containing $500 \mathrm{~g}$ of silage $/ \mathrm{kg}$ of dry matter composed (DM basis) of either 75:25 MS:GS (MS) or 25:75 MS:GS (GS), without or with added NDF from chopped straw and soy hulls $(+47 \mathrm{~g}$ of $\mathrm{NDF} / \mathrm{kg}$ of dry matter). In both experiments, compared with high GS, cows fed high MS had a higher DMI, greater milk production, and lower methane yield (24\% lower in experiment 1 using GF and $8 \%$ lower

\footnotetext{
Received December 14, 2015.

Accepted June 30, 2016.

${ }^{1}$ Present address: AgResearch Grasslands, Palmerston North, New
} Zealand.

${ }^{2}$ Corresponding author: c.k.reynolds@reading.ac.uk
\end{abstract}

in experiment 2 using RC). Added NDF increased (or tended to increase) methane yield for high MS, but not high GS diets. In the separate experiments, the GF and RC methods detected similar dietary treatment effects on methane emission (expressed as $\mathrm{g} / \mathrm{d}$ and $\mathrm{g} / \mathrm{kg}$ of DMI), although the magnitude of the differences varied between experiments. Overall methane emission and yield were $448 \mathrm{~g} / \mathrm{d}$ and $20.9 \mathrm{~g} / \mathrm{kg}$ of DMI for experiment 1 using GF and $458 \mathrm{~g} / \mathrm{d}$ and $23.8 \mathrm{~g} / \mathrm{kg}$ of DMI for experiment 2 using $\mathrm{RC}$, respectively.

Key words: forage, fiber, milk production, methane emission

\section{INTRODUCTION}

The current United Kingdom (UK) National Greenhouse Gas Inventory largely estimates emissions from agriculture using the most simplified (Tier 1) approach to accounting (IPCC, 2007). This approach uses generic assumptions and factors about livestock management to estimate greenhouse gas emissions, and there is a lack of methane emission factors from livestock in different farming systems fed a variety of diets. Analyses of calorimetry data (Mills et al., 2001) have shown that enteric methane emission is affected by dietary concentrations of starch relative to fiber. Previous comparisons have found replacing grass silage (GS) with maize silage (MS) increases milk production from dairy cows, mostly through increased feed intake for MS compared with GS (Phipps et al., 1988, 1992, 1995; O'Mara et al., 1998; Kliem et al., 2008). Enteric methane emission was also found to be variably lower with MS compared with GS diets (Reynolds et al., 2010; Hammond et al., 2015b), although this is not always consistent (Hammond et al., 2015b; Livingstone et al., 2015). An explanation for differences (and also lack of difference) in ruminant methane emission with high MS versus high GS diets may be the physical and chemical attributes of these silages, along with digestive processes associated with the quantity of feed eaten. In the study of Reynolds et al. (2010), high MS 
and high GS diets were formulated to be similar in starch and NDF concentrations by manipulation of the concentration proportion of the diet. It was concluded that observed differences in high MS versus high GS diets on methane emission was attributed to differences in the rate and extent of degradation of carbohydrate components. Intakes of fibrous diets (i.e., GS or diets with high NDF concentration) are not expected to be as high as diets comprising higher proportions of readily fermentable carbohydrates (i.e., MS or diets with high starch concentration) because of increased rumen fill and extended time required to chew and reduce the particle size of fiber to enable passage from the rumen. Considering that MS and GS diets are applicable to rations based on typical UK forages, further work is warranted to examine the effects of forage type and composition on milk production and methane emission from ruminant livestock.

Dietary manipulation can be effective for mitigation of methane emission from dairy cattle, and alternative methods to respiration chambers (RC) are being introduced as a less intrusive way to measure enteric methane emission. Particularly lacking is the capability to accurately measure individual methane emission from multiple animals in a production environment over a long period of time without interference to daily routine. The GreenFeed (GF) system (C-Lock Inc., Rapid City, SD) is a portable sampling unit that is used to estimate individual daily methane emission by integrating measurements of airflow, gas concentration, and detection of head position during each animal's visit to the unit. The animal is free to move and voluntarily enters a hood where an enticement, usually in the form of a feed supplement, is delivered, and while the animal is eating, breath samples are analyzed for methane emission. Depending on GF setup, animals can be free to visit GF at any time of the day or access can be dictated by the investigators. Measurements of methane emission by GF are typically over short periods (3 to $7 \mathrm{~min}$ ) at several variable times within a day, over several days, so that ultimately a 24 -h individual methane emission profile is estimated based on extrapolation from repeated short-term measurements. An indepth description of the GF system for measurement of enteric methane can be obtained from Zimmerman and Zimmerman (2012), Hristov et al. (2015), Huhtanen et al. (2015), and Hammond et al. (2016).

With increasing use of GF, more studies have compared GF estimates with methane measurements using other techniques; however, comparisons with RC are difficult because measurements are not simultaneous. In a summary of GF publications by Hammond et al. (2016), under a variety of conditions, GF, RC, and sul- fur hexafluoride $\left(\mathbf{S F}_{\mathbf{6}}\right)$ techniques are shown to give a similar estimate of daily enteric methane emission for cattle on most occasions. However, it was concluded that suitability of the GF system will be affected by the experimental objectives and design. An example is Hammond et al. (2015a) who used dairy cattle to compare $\mathrm{RC}, \mathrm{GF}$, and $\mathrm{SF}_{6}$ measurement techniques. Although techniques were comparable for measurement of methane emission, it was concluded that further work was needed to determine how to best deploy the GF system to detect significant changes in methane emission attributable to individual animals and treatments, and that future studies should include a greater number of animals per treatment than is required for RC studies.

The primary objective of the present study was to examine the effect of feeding forages differing in MS and GS proportions to lactating dairy cattle, with or without supplemental NDF, on feed intake, milk production and composition, and methane emission. Methane emission was measured using $\mathrm{RC}$ in experiment 2 and GF in experiment 1 , as an alternative method to $\mathrm{RC}$ for measuring dietary effects on methane emission. It was hypothesized that feed intake and milk production would be greater, and methane yield $(\mathrm{g} / \mathrm{kg}$ of $\mathrm{DMI})$ lower for cows fed higher MS diets and diets without additional NDF, compared with higher GS diets and diets with higher NDF concentration.

\section{MATERIALS AND METHODS}

\section{Experimental Design}

Two experiments using the same dietary treatments were undertaken simultaneously at the University of Reading's Centre for Dairy Research (CEDAR, Arborfield, UK). All procedures were approved and monitored under the UK Home Office Animals (Scientific Procedures) Act 1986. Experiment 1 was a 12wk randomized block continuous design experiment. Forty lactating Holstein dairy cows were blocked into 4 treatment groups (10 cows each) based on calving date, parity, and milk yield determined in the 3 wk before the experiment commencing ( $\mathrm{wk}-3$ to -1 , covariate period) when cows were fed a common commercial TMR. For the entire experiment, cows were loose-housed in a yard with sand-bedded cubicles, weighed twice weekly, and fed using an electronic Calan Broadbent individual feeding system allowing measurement of individual cow feed intake (American Calan, Northwood, NH). During a 3 -wk training period before the covariate period (wk -6 to -4 ) and from wk 9 to 12 , cows had variable and voluntary access to a GF unit; however, GF 
measurements of methane were only considered for analysis between wk 10 to 12 . Measurements from cows of experiment 1 included diet composition, feed intake, BW, and milk yield and composition during wk 1 to 8 (production period), and diet composition, feed intake, milk yield, and methane emission during wk 10 to 12 (methane measurement period).

Experiment 2 used 4 lactating Holstein cows surgically fitted with rumen cannulas (type \#1 C, $100 \mathrm{~mm}$ center diameter, Bar Diamond Inc., Parma, ID) in a previous lactation. Experiment 2 was a $4 \times 4$ Latin square design balanced for carryover effects with 5-wk treatment periods. From wk 1 to 3 , animals were grouphoused with access to cubicles bedded with rubber mats and wood shavings, fed TMR diets ad libitum, and milked twice daily. During this time, animals were adapted to dietary treatments with feed intake measured using a roughage intake control feeding system (Insentec B.V., Marknesse, the Netherlands). During wk 4, animals were moved to individual tie stalls and in wk 5 animals were staggered in pairs to 2 individual $\mathrm{RC}$ for 2 consecutive days of methane measurements. Measurements included diet composition, feed intake, and milk yield and composition during wk 4, and DMI, milk yield, and methane emission while in RC during wk 5 . Cows were weighed weekly and before and after measurements in $\mathrm{RC}$.

\section{Animals and Dietary Treatments}

In experiment 1 , cows averaged $( \pm$ SEM $) 74 \pm 16.2$ DIM at the start of the experiment and a BW of 670 $\pm 4.0 \mathrm{~kg}$ throughout the experiment. In experiment 2 , cows averaged $( \pm \mathrm{SEM}) 114 \pm 3.3 \mathrm{DIM}$ at the start of the experiment and $678 \pm 10.5 \mathrm{~kg}$ of $\mathrm{BW}$ throughout the experiment.

Cows in both experiments were fed for ad libitum DMI ( $5 \%$ refusals). In experiment 1 , cows were fed once daily between 0700 and $0900 \mathrm{~h}$, and milked twice daily between 0600 and 0700 h, and 1500 and 1600 h. Feed refusals were collected thrice weekly (Monday, Wednesday, and Friday) for estimates of individual daily DMI. In experiment 2, diets were fed twice daily at 1000 and $1600 \mathrm{~h}$ from wk 1 to 3 , and thereafter (wk 4 to 5 ) were fed 4 times daily at 0500, 1100, 1700, and $2200 \mathrm{~h}$. Feed refusals were collected once daily at $0800 \mathrm{~h}$, and cows were milked twice daily between 0600 and $0700 \mathrm{~h}$, and 1500 and $1600 \mathrm{~h}$.

Dietary treatments fed (Table 1) in both experiments were either a high MS $(375 \mathrm{~g} / \mathrm{kg}$ of DM) and low GS $(125 \mathrm{~g} / \mathrm{kg})$ TMR (MS), or the reverse proportions (GS), without or with additional chopped barley straw and soy hulls incorporated to increase concentration of
NDF $(+47 \mathrm{~g} / \mathrm{kg}$ of DM). For experiment 1 , the TMR was prepared with a Mix Max 10 Paddle Feeder (Hi Spec Engineering Ltd., Bagenalstowm, Republic of Ireland). For experiment 2, each TMR was prepared with a Dataranger (American Calan, Northwood, NH). For both experiments ingredients were added in the order of straw, concentrate mix, calf pellets, limestone, grass silage, and maize silage. Dietary treatments were formulated to be isonitrogenous and meet or exceed the recommendation for MP, minerals, and vitamins based on Feed into Milk (Thomas, 2007) recommendations (Table 1). The GF used for estimating methane emission from individual animals in experiment 1 used calf pellets as a form of enticement to encourage animals to enter the sampling hood. Therefore, dietary treatments were formulated for both experiments to include a commercial calf pellet that was incorporated into the TMR to form $8.7 \%$ of the formulated TMR (DM basis). When the GF was used in experiment 1 (wk 9 to 12), pellets were excluded from the TMR and fed in the GF. Pellets were included in the TMR throughout experiment 2.

The MS was based on a mixture of maize varieties which were combined at harvest (October 22, 2012) and stored in clamps. Grass silage was made from a third cut (August 10, 2012) Lolium perenne mixture of tetra and diploid ryegrass species. The ryegrass was wilted for $24 \mathrm{~h}$ and ensiled with an additive (GENUS ULV, Genus Breeding Ltd., Nantwich, UK; $40 \mathrm{~mL} / \mathrm{t}$ ). Both forage silages remained sealed in clamps for a minimum period of 6 wk before use.

\section{Methane Emission}

For experiment 1, a single GF unit was used to estimate individual cow methane emission during wk 10 to 12. Details of the GF operation and use are given by Zimmerman and Zimmerman (2012), Hammond et al. (2015a), Hristov et al. (2015), and Huhtanen et al. (2015). Briefly, GF operation was initiated when an animal placed its head inside the GF hood. A radio frequency identification reader identified the animal's ear tag and GF sampling was activated when the animal's head (located by an infrared sensor) was located close to the sampling inlet within the hood (muzzle within $30 \mathrm{~cm}$ of the sampling inlet as detailed by Huhtanen et al., 2015), and it was deemed that sufficient time had elapsed since the previous methane measurement for that animal. The position of the animal's head within the hood was monitored using sensors to ensure complete breath collection. The GF unit was set up outside the end of a cubicle yard within a polytunnel that minimized the effect of wind on measurements. 
Table 1. Diet formulations ( $\mathrm{g} / \mathrm{kg}$ of $\mathrm{DM}$ ) for total mixed rations with higher proportions of maize (MS) or grass silage (GS), without or with added NDF (MSNDF and GSNDF) and fed to lactating cows in experiments 1 and 2 and chemical composition (DM basis, $\mathrm{g} / \mathrm{kg}$ ) of diets for experiment 1

\begin{tabular}{|c|c|c|c|c|}
\hline Item & MS & MSNDF & GS & GSNDF \\
\hline Grass silage & 125 & 125 & 375 & 375 \\
\hline Maize silage & 375 & 375 & 125 & 125 \\
\hline Barley straw & 10 & 50 & 10 & 50 \\
\hline Cracked wheat & 91 & 12 & 107 & 38 \\
\hline Maize meal & 0 & 0 & 108 & 103 \\
\hline Molassed sugar beet feed & 50 & 50 & 0 & 0 \\
\hline Soy hulls & 12 & 50 & 0 & 41 \\
\hline Wheat feed & 97 & 84 & 70 & 50 \\
\hline Soybean meal & 97 & 104 & 92 & 105 \\
\hline Rapeseed meal & 30 & 38 & 0 & 0 \\
\hline Molasses & 8 & 8 & 8 & 8 \\
\hline Dicalcium phosphate & 5 & 5 & 5 & 5 \\
\hline Salt & 5 & 5 & 5 & 5 \\
\hline Mineral and vitamin mixture ${ }^{1}$ & 8 & 8 & 8 & 8 \\
\hline Calf pellets ${ }^{2}$ & 87 & 87 & 87 & 87 \\
\hline \multicolumn{5}{|l|}{ Composition, $\mathrm{g} / \mathrm{kg}$ of DM } \\
\hline \multicolumn{5}{|l|}{ Experiment 1 , wk 1 to 8} \\
\hline $\mathrm{DM}, \mathrm{g} / \mathrm{kg}$ of fresh matter & 431 & 430 & 410 & 407 \\
\hline $\mathrm{OM}$ & 927 & 923 & 919 & 907 \\
\hline $\mathrm{CP}$ & 154 & 159 & 159 & 170 \\
\hline NDF & 340 & 391 & 366 & 395 \\
\hline $\mathrm{ADF}$ & 192 & 220 & 219 & 239 \\
\hline Starch & 216 & 179 & 193 & 140 \\
\hline Oil & 39.5 & 37.6 & 42.6 & 43.0 \\
\hline Water-soluble carbohydrate & 45.8 & 38.7 & 40.6 & 40.1 \\
\hline Starch:NDF & 0.64 & 0.46 & 0.53 & 0.35 \\
\hline \multicolumn{5}{|l|}{ Experiment 1 , wk 10 to 12} \\
\hline $\mathrm{DM}, \mathrm{g} / \mathrm{kg}$ of fresh matter & 431 & 435 & 383 & 378 \\
\hline $\mathrm{OM}$ & 927 & 911 & 926 & 899 \\
\hline $\mathrm{CP}$ & 163 & 178 & 168 & 161 \\
\hline NDF & 344 & 411 & 366 & 401 \\
\hline $\mathrm{ADF}$ & 199 & 242 & 223 & 243 \\
\hline Starch & 219 & 144 & 212 & 141 \\
\hline Oil & 37.7 & 37.7 & 41.7 & 45.1 \\
\hline Water-soluble carbohydrate & 40.2 & 35.7 & 36.0 & 25.1 \\
\hline Starch:NDF & 0.64 & 0.35 & 0.58 & 0.35 \\
\hline
\end{tabular}

${ }^{1}$ Containing (per kg): $220 \mathrm{~g}$ of calcium, $40 \mathrm{~g}$ of phosphorus, $50 \mathrm{~g}$ of magnesium, $80 \mathrm{~g}$ of sodium, $30 \mathrm{mg}$ of selenium, $120 \mathrm{mg}$ of cobalt, $400 \mathrm{mg}$ of iodine, 5,000 $\mathrm{mg}$ of manganese, 6,000 $\mathrm{mg}$ of zinc, 3,000 $\mathrm{mg}$ of copper, 400,000 IU of vitamin A, 75,000 IU of vitamin D, 2,600 IU of vitamin E, and $100 \mathrm{mg}$ of biotin.

${ }^{2}$ Chemical composition of calf pellets was ( $\mathrm{g} / \mathrm{kg}$ of DM) ash, 85.1; oil, 46.5; ADF, 174; NDF, 289; starch, 259; water-soluble carbohydrate, 91.3 ; nitrogen, 27.3; CP, 171; and gross energy (MJ/kg), 18.1.

Gates were positioned to allow access to the GF by only 1 animal at a time.

The concentration of gas emitted by the animal was calculated using background gas concentration, the differential concentration of gas during the animal's time in the GF hood, and the calibration coefficient for concentration. See Huhtanen et al. (2015) for detailed calculations of GF-estimated methane emission, which were used here. The calibration coefficient was based on $\mathrm{N}$, carbon dioxide, and methane gases used to calculate the response of the sensors. The GF analyzers were calibrated weekly using a zero baseline gas (oxygen-free $\mathrm{N}$ ) and a span gas mixture of $\mathrm{N}$ containing $5,000 \mathrm{mg} / \mathrm{kg}$ carbon dioxide and $1,000 \mathrm{mg} / \mathrm{kg}$ methane (BOC Ltd., Manchester, UK). This was to account for any drift in the calibration of the analyzers, which was found to be negligible. A gravimetrically measured amount of carbon dioxide gas was released where the animals nose would be when feeding to check recovery of expired gases at the beginning and end of the measurement period. No recovery correction was required in the current study. Data from GF were downloaded on a daily basis through a web-based data management system provided by C-Lock Inc.

Animals were adapted to GF use before the covariate period (wk -6 to -4 ) and again in wk 9, with methane measurements used for statistical analysis obtained during wk 10 to 12 . During these periods, animals were able to access the GF unit at any time, except during milking and provided it was not in use by another 
animal. However, this did not necessarily generate a measurement of methane. A visit was defined as a successful methane measurement facilitated by feed delivery which could only occur when a specified time ( $>240 \mathrm{~min}$ ) had elapsed since the previous visit. In this case, the enticement was provided and a visit logged if the animal remained correctly positioned in the unit for a sufficient amount of time $(>3 \mathrm{~min})$ for a valid methane measurement. The unit was programmed to deliver feed in 50-g quantities at varying intervals over a 6 -min period, so that up to $350 \mathrm{~g}$ of pellet fresh weight was delivered during each complete visit, with up to a maximum of 6 visits per day ( $2 \mathrm{~kg}$ of $\mathrm{DM})$.

For experiment 2, measurement of gaseous exchange was obtained over 2 consecutive days in wk 5 using open-circuit respiration chambers and methods similar to those described by Cammell et al. $(1981,1986)$ and Reynolds et al. $(2001,2014)$. The chambers $\left(22.3 \mathrm{~m}^{3}\right.$ capacity) were constructed from double-skin insulated steel panels and fitted with a profiled concrete floor with rubber mats, tubular steel sides to the standing, and neck yoke and food box arrangements similar to those in the main experimental unit. Glazed panels were fitted internally and externally to the chambers, so the animals had visual contact both between chambers and their local surroundings. An airlock of approximately $5.2 \mathrm{~m}^{3}$ was provided for service access to the feces and urine balance equipment and for routine milking and animal inspection and was connected to the main chamber via double doors. Each chamber was fitted with a re-circulatory air conditioning system (Mueller, Caswell Refrigeration Ltd., Malmesbury, Wiltshire, UK) to provide air movement of up to 20 times the chamber volume per hour, environmental control across a temperature range of 12 to $25^{\circ} \mathrm{C} \pm$ $2^{\circ} \mathrm{C}$ and a relative humidity of $60 \pm 10 \%$. The present experiment was conducted using 6 air changes per hour with environmental controls adjusted to give no more than $\pm 3^{\circ} \mathrm{C}$ difference from the cowshed environment. The rate of air flow through the outlet ducting from the chambers was measured using factory-calibrated turbine flow-meters (AOT Systems, Andover, Hampshire, UK). Monitoring of temperature and relative humidity in the exhaust air flows was by type RHA1 sensors (Delta-T Devices Ltd., Burwell, Cambridge, UK). The concentrations of oxygen in exhaust air flow was measured by a dual-channel paramagnetic oxygen analyzer (Servomex International Ltd., Crowborough, Sussex, UK), and carbon dioxide and methane concentrations were measured by dedicated dual-channel infrared gas analyzers (ADC Manufacturing Ltd., Stanstead Abbotts, Hertfordshire, UK). The gas analysis train was designed to allow automatic measurement at 4-min intervals from each chamber, giving 15 values per chamber per hour, with automatic zero and span calibration readings at 4 -h intervals. Signal outputs from monitoring and gas analysis equipment were recorded by a data logger (type DL2e, Delta-T Devices Ltd.). The data were automatically downloaded and compiled during each 24-h period using a desktop computer and associated software programs (7th Wave Software Ltd., Pangbourne, Berkshire, UK) based on specifically designed data logging programs. Heat production was estimated from gaseous exchange and urinary $\mathrm{N}$ output using the equation of Brouwer (1965).

\section{Sample Collection and Analyses}

For experiment 1, from wk 1 to 12 samples of TMR offered were taken 3 times per wk and frozen before a representative monthly bulk sample was created. This was oven-dried (model ME/850/DIG/A, Genlab Ltd., Widnes, UK) at $65^{\circ} \mathrm{C}$ for $48 \mathrm{~h}(\# 930.15$, AOAC International, 2005), ground, and stored for analyses of chemical composition. An additional sample of the bulked TMR was also oven-dried at $100^{\circ} \mathrm{C}$ for $\mathrm{DM}$ determination (\#930.15, AOAC International, 2005). Total mixed ration refusals and their corresponding $\mathrm{DM}$ (oven-dried at $100^{\circ} \mathrm{C}$ for $24 \mathrm{~h}$ ) were measured thrice weekly and DMI calculated on a weekly basis. Milk production was determined daily throughout the experiment and milk samples $(30 \mathrm{~mL})$ were taken from 2 successive a.m. and p.m. milkings at weekly intervals and preserved with potassium dichromate $(1 \mathrm{mg} / \mathrm{mL}$; Lactabs, Thomson and Capper, Runcorn, UK) for the determination of milk composition during wk 1 to 8 .

For experiment 2, the TMR offered and refused was collected daily from individual cows during wk 4 and 5 for DMI determination by oven-drying at $100^{\circ} \mathrm{C}$ for $24 \mathrm{~h}$. Additional daily samples were taken during wk 4 and pooled for individual cows to make a composite sample that was stored at $-20^{\circ} \mathrm{C}$ for analyses of chemical composition. Milk production was determined daily throughout the experiment. Milk samples $(30 \mathrm{~mL})$ were taken at every milking in wk 4 and preserved with potassium dichromate for the determination of milk composition.

Samples of the TMR offered and refused for both experiments were analyzed by wet chemistry as detailed by Hammond et al. (2014). Samples were analyzed for N (macro Kjeldahl method), NDF and ADF (procedures of Robertson and Van Soest, 1981, and Mertens, 2002), starch (enzymatic conversion to glucose and glucose measured using amyloglucosidase), oil (acid extraction), water-soluble carbohydrates (Nelson-Somogyi procedure), and ash (combustion) concentrations. Milk 
samples were analyzed using mid-infrared spectroscopy (Foss Electric Ltd., York, UK) to determine fat, protein, casein, lactose, and MUN concentrations, and $4 \%$ FCM and ECM yields were calculated as detailed by Gaines (1928) and Gaillard et al. (2016), respectively.

\section{Statistical Analyses}

For experiment 1, weekly means of variables measured for each cow were statistically analyzed from wk 1 to 8 (production period) and wk 10 to 12 (methane measurement period) separately. The methane emission data statistically analyzed were the daily averages for individual animals for the 3-wk measurement period. Data were analyzed using the MIXED Procedure of SAS Version 9.2 (2011, SAS Institute Inc., Cary, NC) and a model testing for fixed effects of forage type (1 df), added NDF treatment (1 df) and their interaction (1 df), their 2-way and 3-way interactions, random effects of cow, and repeated effects of week within cow using the covariance structure (compound symmetry, heterogeneous compound symmetry, autoregressive, heterogeneous autoregressive or unstructured) giving the best fit based on the lowest Bayesian information criterion (BIC) value for each variable of interest. In addition, averages of weekly measurements during the 3 -wk covariate period were used as a covariate in the statistical analysis.

For experiment 2, means of variables measured for each cow and period were used in the statistical analysis. Data were analyzed using the MIXED Procedure of SAS (as for experiment 1) and a model testing the fixed effects of forage type $(1 \mathrm{df})$, added NDF treatment (1 df) and their interaction (1 df), and random effects of cow $(3 \mathrm{df})$ and the repeated effect of period ( $3 \mathrm{df})$ using the covariance structure (compound symmetry, heterogeneous compound symmetry, autoregressive, heterogeneous autoregressive or unstructured) giving the best fit based on lowest BIC value for each variable of interest. Methane emission data from both experiments were analyzed for homogenous distribution and outliers using the Univariate Procedure of SAS and residual analysis using the Mixed Procedure. Least squares means are reported.

\section{RESULTS}

\section{Diet Composition}

Differences in diet composition observed for bulk samples taken during the production and methane measurement periods of experiment 1 (Table 1) were similar to differences observed for experiment 2 (Table 2 ). For experiment 2, high MS diets had greater DM $(P<0.001)$ and $\mathrm{OM}(P=0.002)$ contents, a greater concentration of starch $(P<0.001)$, and lower concentrations of $\mathrm{CP}(P=0.077), \mathrm{NDF}(P=0.025), \operatorname{ADF}(P$ $=0.005)$, and oil $(P=0.002)$, compared with high GS diets (Table 2). No forage type effect was observed on water-soluble carbohydrate. Added NDF increased concentrations of $\operatorname{NDF}(P=0.006)$ and $\operatorname{ADF}(P=0.002)$, and decreased starch concentration $(P<0.001)$. Forage type $\times$ NDF treatment interactions were found for concentrations of OM $(P=0.074), \mathrm{CP}(P=0.096)$, starch $(P=0.094)$, and oil $(P=0.036)$. The starch:NDF ratio was higher for high MS diets $(P=0.004)$ and decreased with added NDF $(P=0.002)$.

\section{Animal Performance}

Intakes of individual dietary components are given in Table 3 for both experiments 1 and 2. Cows fed

Table 2. Chemical composition (DM basis, $\mathrm{g} / \mathrm{kg}$ ) of high maize (MS) or high grass silage (GS) forage diets without or with additional NDF (MSNDF and GSNDF) for experiment 2

\begin{tabular}{|c|c|c|c|c|c|c|c|c|}
\hline \multirow[b]{2}{*}{ Item } & \multicolumn{4}{|c|}{ Dietary treatment } & \multirow[b]{2}{*}{ SEM } & \multicolumn{3}{|c|}{$P$-value } \\
\hline & MS & MSNDF & GS & GSNDF & & Forage type & NDF & $\begin{array}{c}\text { Forage type } \\
\times \mathrm{NDF}\end{array}$ \\
\hline \multicolumn{9}{|l|}{ Experiment 2, wk 4} \\
\hline DM, $\mathrm{g} / \mathrm{kg}$ of fresh matter & 425 & 425 & 401 & 397 & 6.50 & $<0.001$ & 0.341 & 0.326 \\
\hline $\mathrm{OM}$ & 930 & 922 & 911 & 914 & 2.49 & 0.002 & 0.299 & 0.074 \\
\hline $\mathrm{CP}$ & 164 & 140 & 169 & 181 & 7.74 & 0.077 & 0.265 & 0.096 \\
\hline NDF & 307 & 369 & 354 & 385 & 10.50 & 0.025 & 0.006 & 0.172 \\
\hline $\mathrm{ADF}$ & 172 & 214 & 201 & 239 & 7.06 & 0.005 & 0.002 & 0.747 \\
\hline Starch & 247 & 196 & 193 & 137 & 5.51 & $<0.001$ & $<0.001$ & 0.094 \\
\hline Oil & 35.9 & 36.3 & 44.7 & 42.2 & 0.42 & 0.002 & 0.135 & 0.036 \\
\hline $\mathrm{WSCHO}^{1}$ & 48.2 & 43.6 & 41.4 & 38.3 & 5.23 & 0.250 & 0.436 & 0.873 \\
\hline Starch:NDF & 0.82 & 0.51 & 0.56 & 0.37 & 0.04 & 0.004 & 0.002 & 0.209 \\
\hline
\end{tabular}

${ }^{1}$ Water-soluble carbohydrate. 


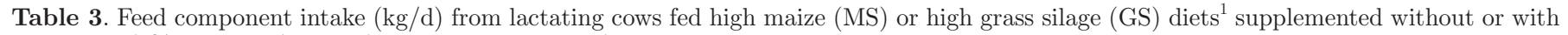
additional (5\% DM basis) NDF (MSNDF and GSNDF) in experiments 1 and 2

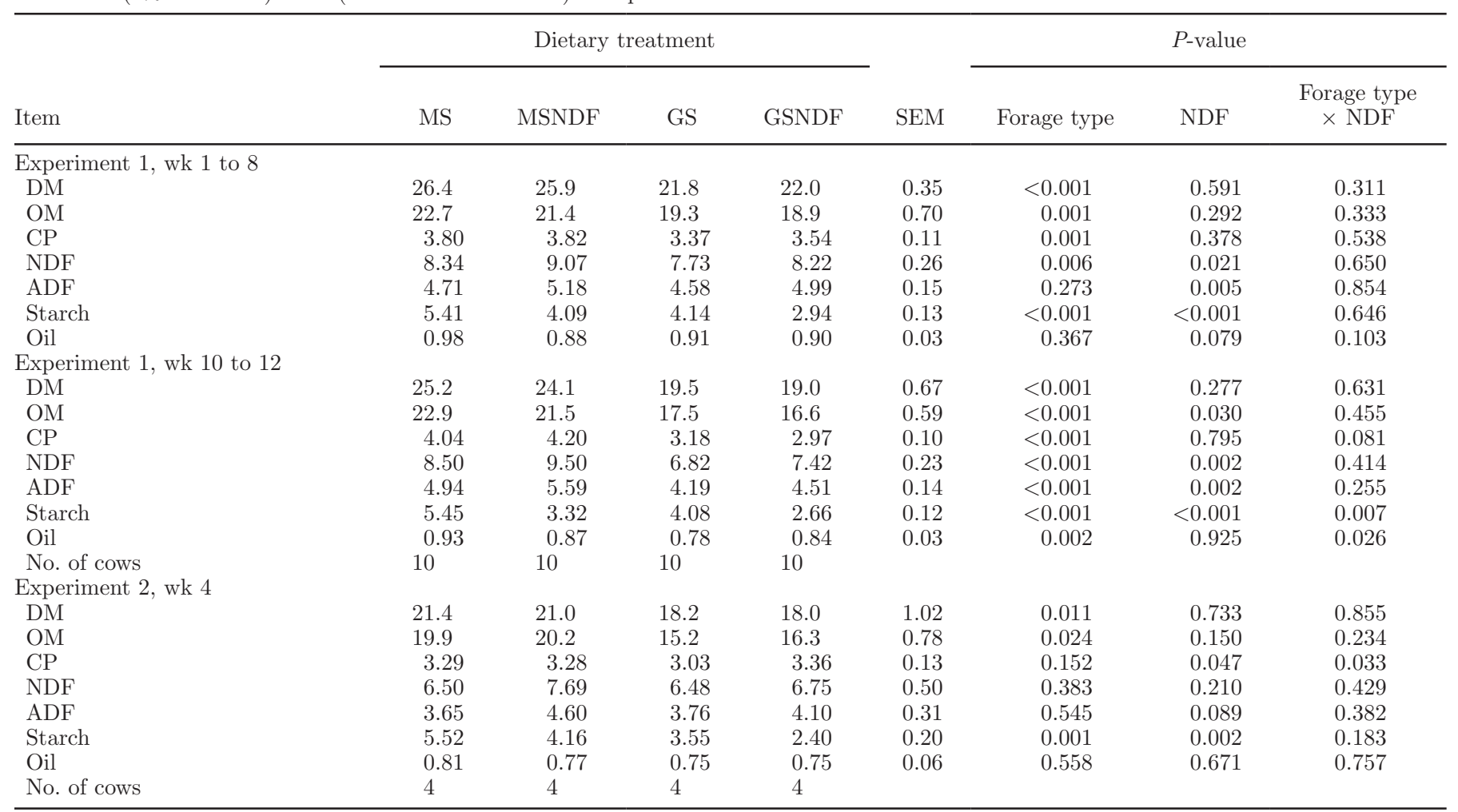

${ }^{1}$ Containing (DM basis) either 37.5 and $12.5 \%$ (MS) or 12.5 and $37.5 \%$ (GS) MS and GS, respectively.

high MS diets in experiment 1 during wk 1 to 8 had greater intakes of DM $(P<0.001)$, OM $(P=0.001)$, $\mathrm{CP}(P=0.001), \mathrm{NDF}(P=0.006)$, and $\operatorname{starch}(P$ $<0.001)$, compared with high GS, with no effect on intakes of ADF and oil. Added NDF treatment increased intakes of $\mathrm{NDF}(P=0.021)$ and $\operatorname{ADF}(P=$ $0.005)$, and decreased intakes of starch $(P<0.001)$ and oil $(P=0.079)$, with no effects on intakes of DM, OM, or CP. During wk 10 to 12 in experiment 1 , cows fed high MS diets had higher $(P<0.01)$ intakes of all individual dietary components, compared with cows fed high GS diets. Adding NDF decreased intakes of OM $(P=0.030)$ and starch $(P<0.001)$, and increased intakes of $\mathrm{NDF}(P=0.002)$ and $\operatorname{ADF}(P=0.002)$. A forage type $\times \mathrm{NDF}$ treatment interaction was found for intakes of $\mathrm{CP}(P=0.0 .081)$, starch $(P=0.007)$, and oil $(P=0.026)$.

Cows fed high MS diets in experiment 2 had greater intakes of DM $(P=0.011)$, OM $(P=0.024)$, and starch $(P=0.001)$, compared with high GS diets. Forage type had no effect on intakes of $\mathrm{CP}, \mathrm{NDF}, \mathrm{ADF}$, or oil. Added NDF increased ADF intake $(P=0.089)$ and decreased intake of starch $(P=0.002)$. A forage type $\times \mathrm{NDF}$ treatment interaction was found for intake of $\mathrm{CP}(P=0.033)$.
Production data (including BW, milk yield, and composition) were collected from cows of experiment 1 during wk 1 to 8 (Table 4). During this period, cows fed high MS diets had a greater BW $(P=0.002$, which was due to a greater average daily live weight gain; data not shown) and milk yield $(P=0.001)$ than cows fed high GS, with no effect of NDF treatment. There were no forage type or NDF treatment effects on FCM, but cows fed high MS diets produced more ECM $(P=$ $0.031)$. Yields $(\mathrm{g} / \mathrm{d})$ of milk protein $(P=0.001)$, lactose $(P=0.001)$, and casein $(P=0.001)$ were greater for cows fed high MS than high GS diets, and added NDF decreased milk protein $(P=0.031)$ and casein $(P=$ 0.049 ) yields. Forage type affected concentrations (g/ $\mathrm{kg}$ ) of milk fat (MS lower than GS; $P=0.018$ ), lactose (MS higher than GS; $P=0.011$ ), and casein (MS higher than GS; $P=0.053$ ). Milk urea concentration was lower $(P<0.001)$ for high MS compared with high GS diets. Added NDF increased milk fat concentration $(P=0.041)$, with a significant forage type $\times \mathrm{NDF}$ treatment interaction $(P=0.049)$ due to a greater increase for high MS than for high GS diets. Added NDF decreased milk protein $(P=0.021)$ and casein $(P=$ 0.066 ) concentrations, whereas milk urea concentration increased $(P=0.001)$. 
In experiment 2, cows fed high MS had a greater BW $(P=0.015)$ and milk yield $(P=0.076)$, than cows fed high GS diets, with no effect of NDF treatment (Table $4)$. No effect was found of forage type or NDF treatments on FCM or ECM yields. Cows fed high MS had greater yields of milk protein $(P=0.043)$, lactose $(P$ $=0.060)$, and casein $(P=0.048)$, compared with high GS diets, with no effect of NDF treatment. No effect was found of forage type or NDF treatments on milk component concentrations, except for milk urea, which tended to be lower $(P=0.066)$ for MS than GS.

\section{Methane Emission}

During methane measurements in experiment 1 (Table 5), DMI was higher $(P<0.001)$ for the high MS compared with high GS diets, and not affected by
NDF addition. Similarly, milk $(P=0.003)$ and ECM $(P$ $=0.017$ ) yields were higher for the high MS compared with the high GS diets, and there was no effect of NDF addition. Methane production was not affected by forage type or NDF treatments (averaging $448 \mathrm{~g} / \mathrm{d}$ ), but a forage type $\times \mathrm{NDF}$ treatment interaction trend $(P=$ 0.096) was found, with methane emission being lowest for high MS diets without additional NDF. Methane yield $(\mathrm{g} / \mathrm{kg}$ of DMI) was $24 \%$ lower $(P<0.001)$ for cows fed high MS compared with high GS, and added NDF increased $(P=0.064)$ methane yield for high MS diets, but not high GS diets (forage type $\times$ NDF treatment interaction, $P=0.093)$. Methane expressed per unit of milk and ECM yields (g/kg of milk) were lower $(P=0.001)$ for cows fed high MS compared with high GS, and increased with added NDF $(P=0.016)$. Methane per kilogram of $\mathrm{BW}$ tended to increase for high

Table 4. Body weight, milk yield, and composition from lactating cows fed high maize (MS) or high grass silage (GS) diets ${ }^{1}$ supplemented without or with additional (5\% DM basis) NDF (MSNDF and GSNDF) in experiments 1 and 2

\begin{tabular}{|c|c|c|c|c|c|c|c|c|}
\hline \multirow[b]{2}{*}{ Item } & \multicolumn{4}{|c|}{ Dietary treatment } & \multirow[b]{2}{*}{ SEM } & \multicolumn{3}{|c|}{$P$-value } \\
\hline & MS & MSNDF & GS & GSNDF & & Forage type & $\mathrm{NDF}$ & $\begin{array}{l}\text { Forage type } \\
\quad \times \mathrm{NDF}\end{array}$ \\
\hline \multicolumn{9}{|c|}{ Experiment 1 , wk 1 to 8} \\
\hline $\mathrm{BW}, \mathrm{kg}$ & 677 & 677 & 665 & 661 & 3.87 & 0.002 & 0.686 & 0.673 \\
\hline \multicolumn{9}{|l|}{ Yield } \\
\hline Milk, kg/d & 38.4 & 37.1 & 35.4 & 34.5 & 0.74 & 0.001 & 0.155 & 0.311 \\
\hline Fat, $\mathrm{g} / \mathrm{d}$ & 1,302 & 1,386 & 1,343 & 1,311 & 42.6 & 0.703 & 0.537 & 0.158 \\
\hline Protein, g/d & 1,211 & 1,144 & 1,099 & 1,057 & 24.4 & 0.001 & 0.031 & 0.586 \\
\hline Lactose, $\mathrm{g} / \mathrm{d}$ & 1,723 & 1,673 & 1,576 & 1,532 & 36.7 & 0.001 & 0.204 & 0.925 \\
\hline Casein, g/d & 883 & 838 & 801 & 769 & 18.6 & 0.001 & 0.049 & 0.718 \\
\hline \multicolumn{9}{|l|}{ Concentration } \\
\hline Fat, $\mathrm{g} / \mathrm{kg}$ & 34.0 & 37.7 & 38.2 & 38.3 & 0.91 & 0.018 & 0.041 & 0.049 \\
\hline Protein, $\mathrm{g} / \mathrm{kg}$ & 31.7 & 31.0 & 31.2 & 30.8 & 0.21 & 0.111 & 0.021 & 0.519 \\
\hline \multicolumn{9}{|c|}{$\begin{array}{l}\text { No. of cows } \\
\text { Experiment } 2 \text {, wk } 4\end{array}$} \\
\hline $\mathrm{BW}, \mathrm{kg}$ & 693 & 688 & 664 & 676 & 21.5 & 0.015 & 0.587 & 0.172 \\
\hline \multicolumn{9}{|l|}{$\begin{array}{l}\text { Yield } \\
\text { Yis }\end{array}$} \\
\hline Milk, kg/d & 31.6 & 33.6 & 27.4 & 25.8 & 2.05 & 0.076 & 0.807 & 0.243 \\
\hline $\mathrm{FCM}, \mathrm{kg} / \mathrm{d}$ & 29.6 & 30.8 & 29.6 & 25.5 & 2.39 & 0.256 & 0.583 & 0.296 \\
\hline ECM, kg/d & 29.2 & 29.7 & 28.3 & 24.3 & 2.55 & 0.174 & 0.492 & 0.343 \\
\hline Fat, g/d & 1,135 & 1,211 & 1,118 & 1,017 & 103 & 0.313 & 0.908 & 0.392 \\
\hline Protein, g/d & 1,035 & 977 & 917 & 779 & 69.4 & 0.043 & 0.217 & 0.534 \\
\hline Lactose, $\mathrm{g} / \mathrm{d}$ & 1,451 & 1,445 & 1,369 & 1,141 & 6.70 & 0.060 & 0.290 & 0.253 \\
\hline Casein, g/d & 765 & 718 & 667 & 568 & 54.9 & 0.048 & 0.247 & 0.616 \\
\hline \multicolumn{9}{|l|}{ Concentration } \\
\hline Fat, $\mathrm{g} / \mathrm{kg}$ & 32.0 & 39.6 & 37.8 & 40.8 & 3.37 & 0.467 & 0.410 & 0.640 \\
\hline Protein, g/kg & 32.7 & 31.2 & 30.4 & 30.3 & 1.12 & 0.108 & 0.402 & 0.380 \\
\hline Lactose, $\mathrm{g} / \mathrm{kg}$ & 45.4 & 45.6 & 44.7 & 44.8 & 0.40 & 0.153 & 0.767 & 0.996 \\
\hline
\end{tabular}

${ }^{1}$ Containing (DM basis) either 37.5 and $12.5 \%$ (MS) or 12.5 and $37.5 \%$ (GS) MS and GS, respectively. 
Table 5. Methane emissions from lactating cows fed high maize (MS) or high grass silage (GS) TMR ${ }^{1}$ supplemented without or with additional (5\% DM basis) NDF (MSNDF and GSNDF) and obtained using a GreenFeed unit (experiment 1) or respiration chambers (experiment 2)

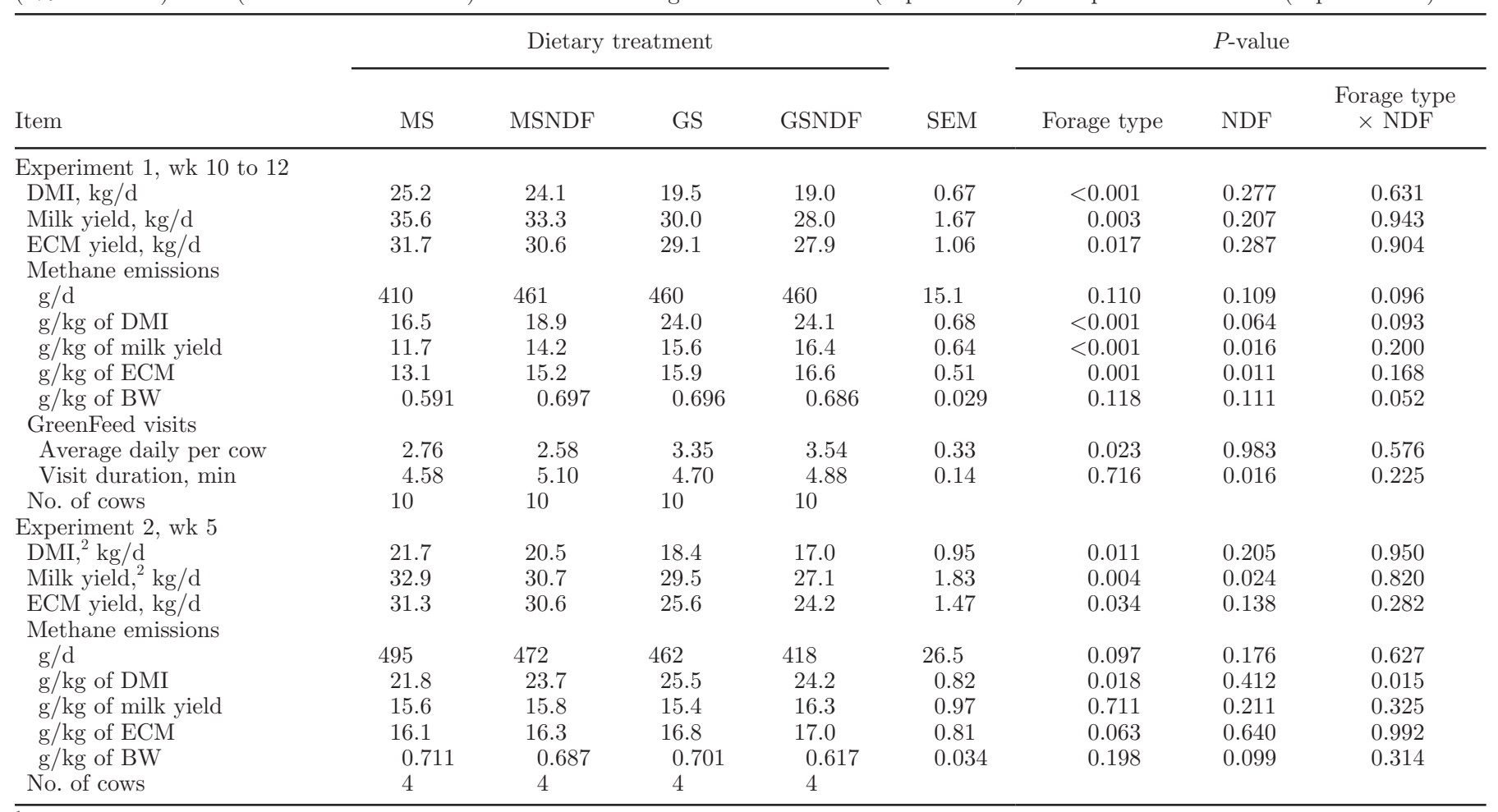

${ }^{1}$ Containing (DM basis) either 37.5 and $12.5 \%$ (MS) or 12.5 and $37.5 \%$ (GS) MS and GS, respectively.

${ }^{2}$ Measurements of DMI and milk yield were taken while animals were housed in respiration chambers and so were obtained alongside measurements of methane emission.

MS diets with additional NDF, but did not increase when NDF was added to GS diets (forage type $\times$ NDF treatment interaction, $P=0.052$ ).

During methane measurements in experiment 2 (Table 5), DMI was higher $(P=0.011)$ for high MS compared with high GS diets, and no effect of NDF treatment was found. Cows fed high MS during methane measurements had a higher milk yield $(P=0.004)$ and ECM yield $(P=0.034)$ than cows fed high GS, and added NDF decreased milk yield $(P=0.024)$. Methane production $(\mathrm{g} / \mathrm{d})$ tended to be higher $(P=0.097)$ for cows fed high MS compared with high GS, with no effect of NDF treatment. Methane yield ( $\mathrm{g} / \mathrm{kg}$ of DMI) was $8 \%$ lower $(P=0.018)$ for cows fed high MS compared with high GS diets. Although there was no effect of NDF treatment, there was a significant forage type $\times$ NDF treatment interaction $(P=0.015)$, with added NDF increasing methane yield for high MS, but not for high GS diets, as observed in experiment 1. There was no effect of forage type when methane was expressed per unit of milk yield ( $\mathrm{g} / \mathrm{kg}$ of milk), but methane per kilogram of ECM yield tended to be lower for high MS $\operatorname{diets}(P=0.063)$. Methane per kilogram of BW tended to be lower when diets included additional NDF $(P=$ 0.099).

\section{Methane Measurement Techniques}

The present experiments were conducted simultaneously using lactating dairy cows of a similar BW fed the same dietary treatments. Although methane emission measurements obtained using $\mathrm{GF}$ and $\mathrm{RC}$ were not statistically comparable, an objective was to determine if dietary treatment effects on methane emission would be detected using both techniques.

When the GF technique was used, 2,567 visits were made to the GF by 40 cows over 3 wk. The average time that methane was sampled from each animal during each GF visit was 4.8 min (Table 5), with an average of 3.0 visits/animal per $\mathrm{d}$, with $94 \%$ of cows visiting the GF every day during the 3 wk of GF access. This resulted in approximately $5 \mathrm{~h}$ of methane measurements for each cow in experiment 1 . Cows housed in RC had 2 consecutive days of approximately $23 \mathrm{~h}$ of methane measurements, which was equivalent to $184 \mathrm{~h}$ of methane measurements for each cow in experiment 2 . 
The number of visits to the GF was affected by dietary treatment, whereby cows fed MS diets visited the GF less frequently on a daily basis than cows fed GS diets $(P=0.023$; Table 5$)$. Cows fed added NDF had a longer GF visit duration than diets without added NDF $(P=0.016)$. The pattern of cow visitation to the GF, based on all cow visits during the 3 -wk measurement period and cumulated over $24 \mathrm{~h}$, is given in Figure 1.

For methane production (g/d), a tendency for a forage type effect was observed using RC in experiment 2 $(P=0.097)$, but not with GF in experiment 1 . Methane yield $(\mathrm{g} / \mathrm{kg}$ of DMI) was measured to be lower from lactating cows fed high MS diets compared with high GS diets, using both GF $(P<0.001)$ and $\mathrm{RC}(P=0.018)$ techniques, but the magnitude of the difference varied between techniques (24 vs. $8 \%$ lower for high MS vs. high GS diets for GF and RC techniques, respectively). For both experiments, there was (or tended to be) a forage type $\times \mathrm{NDF}$ treatment interaction $(P=0.093$ for $\mathrm{GF}$ and $P=0.015$ for RC) when methane emission was expressed per unit of DMI, with methane yield increasing with NDF addition for high MS diets, but not high GS diets. When methane was expressed per unit of milk yield $(\mathrm{g} / \mathrm{kg}$ of milk), there were forage type $(P<0.001)$ and NDF treatment $(P=0.016)$ effects measured with GF, but not RC. Averaging $( \pm$ SEM) methane emission across dietary treatments for each technique gave similar results for both methane production (GF, $448 \pm 5.70$ vs. RC, $458 \pm 12.54 \mathrm{~g} / \mathrm{d}$ ) and methane yield (GF, $20.9 \pm 0.38$ vs. RC, $23.8 \pm 0.73 \mathrm{~g} /$ $\mathrm{kg}$ of DMI).

For GF measurements of methane, the range in methane production and yield (lowest to highest value) was 256 to $567 \mathrm{~g} / \mathrm{d}$ and 14 to $29 \mathrm{~g} / \mathrm{kg}$ of DMI, respectively. The between-animal coefficient of variation for GF methane production and yield was 5.7 and $5.2 \%$, respectively, and the within-animal coefficient of variation for methane production and yield was 10.5 and $14.4 \%$, respectively. For RC measurements, the range in methane production and yield was 387 to $566 \mathrm{~g} / \mathrm{d}$ and 19 to $29 \mathrm{~g} / \mathrm{kg}$ of DMI, respectively. The betweenanimal coefficient of variation for methane production and yield using RC was 8.2 and $7.3 \%$, respectively, and the within-animal coefficient of variation for methane production and yield was 6.7 and $6.4 \%$, respectively. Repeatability for measurements of methane production and yield (calculated as described by Herskin et al., 2003) for experiment 1 was 0.772 and 0.745 , respectively and for experiment 2 was 0.761 and 0.764 , respectively.

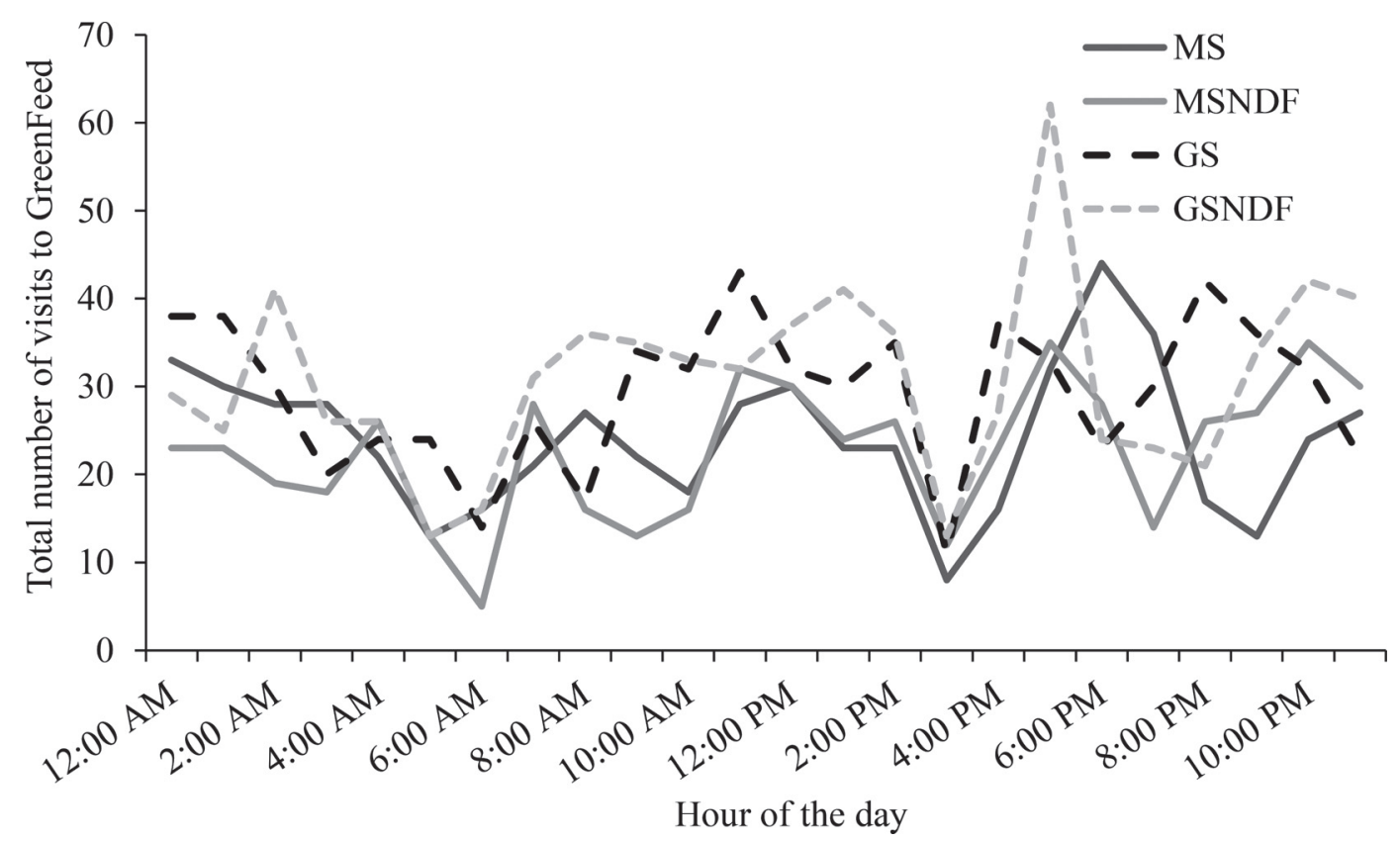

Figure 1. Pattern of GreenFeed (GF) visitation, based on 3 wk of access to a single GF unit, cumulated over a 24-h period, for 40 lactating dairy cows fed 4 dietary treatments of maize silage (MS), MS with added NDF (MSNDF), grass silage (GS), and GS with added NDF (GSNDF). Animals had unlimited access to GF during the $3 \mathrm{wk}$, except during milking (which occurred twice daily between 0600 and $0700 \mathrm{~h}$ and 1500 and $1400 \mathrm{~h}$ ) and if another animal was occupying the unit. 


\section{DISCUSSION}

\section{Effect of Forage Type and Added NDF on Dairy Cow Performance}

Overall, in this study, high MS diets were higher in starch and lower in NDF concentrations compared with high GS diets. The addition of straw and soyhulls decreased starch and increased fiber concentrations for both MS- and GS-based diets. Differences were observed in dietary treatment composition between wk 1 to 8 and wk 10 to 12 in experiment 1 . The high MS diets had higher fiber and lower starch concentrations in wk 10 to 12, and the high GS diets had higher starch concentration, compared with the same respective diets fed in wk 1 to 8 . This was largely due to the influence of variable amounts of pellets dispensed by the GF unit during wk 9 to 12 . The GF unit was only available during wk 9 to 12 , and during this period concentrate pellets were removed from the TMR and instead provided via the $\mathrm{GF}$ as enticement to generate a measure of methane, with an allowance of up to $2 \mathrm{~kg}$ of DM/cow per day. The amount of pellet animals received was dependent on actual visits to the unit, and although up to 6 visits/d were possible for each dietary treatment, the number of visits achieved fell below this target. There were more visits to the GF unit by animals fed high GS diets than by animals fed high MS diets (Table 5; 3.4 vs. 2.7 visits/animal per day).

As observed in previous studies (as reviewed by Kahn et al., 2015), the higher starch and lower fiber contents of high MS diets were likely to be responsible for increased DMI and milk yield for cows in both experiments, compared with high GS diets. Khan et al. (2015) summarized data from 13 published studies with 37 direct comparisons that showed inclusion of MS in a GS-based diets fed to dairy cows improved DMI by 2 $\mathrm{kg} / \mathrm{d}$, milk yield by $1.9 \mathrm{~kg} / \mathrm{d}$, and milk protein concentration by $1.2 \mathrm{~g} / \mathrm{kg}$, with significant increases in yields of milk protein, fat, and lactose. A similar trend was found in this study whereby, compared with high GS diets, high MS improved DMI by $5.4 \mathrm{~kg} / \mathrm{d}$, milk yield by $5.4 \mathrm{~kg} / \mathrm{d}$, and milk protein concentration by $0.35 \mathrm{~g} /$ $\mathrm{kg}$ for cows fed over $8 \mathrm{wk}$ in experiment 1 , and respective improvements of $3.4 \mathrm{~kg} / \mathrm{d}, 6 \mathrm{~kg} / \mathrm{d}$, and $1.6 \mathrm{~g} / \mathrm{kg}$ for cows fed over $4 \mathrm{wk}$ in experiment 2 . The high feed intake of MS is the main driver of greater milk yields, with multiple mechanisms regulating DMI such as NDF and starch content, rate of degradability, and rate of rumen passage (Khan et al., 2015). The higher feed intakes for lactating cows of experiment 1 compared with cows of experiment 2 were likely due to several factors including milk yield, DIM, tie stalls, and experimental design. Dietary treatments were crossed over for cows in experiment 2 and had shorter periods of adaptation (3 wk), compared the continuous design of experiment 1 where animals were maintained on the same diet for the entire experimental duration.

In this study, adding NDF to the diet had no significant effects on DMI or milk yield for cows of either experiments 1 or 2, except it decreased milk yield in wk 5 of experiment 2. For cows of experiment 1 , added NDF decreased milk protein yield and concentration, reflecting a decrease in diet ME concentration and rate and extent of digestible carbohydrate supply. In a study by Kendall et al. (2009), early lactation cows fed $28 \%$ NDF and highly digestible NDF diets produced more milk, fat, and protein than those consuming $32 \% \mathrm{NDF}$ and low digestible NDF diets. Dry matter intake was also greater for cows consuming $28 \%$ NDF diets, but this was not affected by NDF digestibility.

\section{Effect of Forage Type and NDF Concentration on Methane Emissions}

The positive relationship between DMI $(\mathrm{kg} / \mathrm{d})$ and methane emission $(\mathrm{g} / \mathrm{d})$ is thoroughly documented in the literature (e.g., Mills et al., 2001) and also observed in the present study, with a slope of $4.19 \pm 1.53$ and $12.10 \pm 4.3$ for experiments 1 and 2 , respectively $(P=$ 0.01 and $P=0.02$, respectively). Previous comparisons have found replacing GS with MS decreased methane emission and yield to varying extents. Reynolds et al. (2010), McCourt et al. (2007), Brask et al. (2013), and van Gastelen et al. (2015) all reported higher feed intakes and lower methane yields for lactating cows offered MS compared with GS, but no subsequent effect on milk production. However, Staerfl et al. (2012), Hammond et al. (2015b), and Livingstone et al. (2015) have reported inconsistent effects of high MS versus high GS diets on cattle methane emission. In our study, cows fed high MS and high GS diets had similar methane production $(\mathrm{g} / \mathrm{d}$ ) in experiment 1 (with a significant forage type $\times$ NDF treatment interaction), but greater methane production on a high MS diet in experiment 2. For both experiments, cows fed high MS had a lower methane yield compared with high GS diets (24\% lower in experiment 1 using GF and $8 \%$ lower in experiment 2 using RC). Cows fed high MS diets had greater milk yields than cows fed high GS diets; however, when expressing methane per unit of milk yield, only in experiment 1 did cows fed high MS have a lower methane output per unit milk produced compared with high GS. The lower methane yield for the high MS diets is likely attributed to the source of starch and NDF affecting rates of fermentation in the rumen. High 
starch diets are known to be an effective method for lowering enteric methane emission (Beauchemin et al., 2008). Increased intake of starch enhances fermentation pathways that decrease methane production. With increasing dietary starch concentration, rumen $\mathrm{pH}$ is lowered, which can decrease fiber digestion and cause an inhibition of methanogen activity and therefore methane production (Janssen, 2010). Livingstone et al. (2015) found no effect on methane yield when replacing GS with MS in a TMR for lactating dairy cows and concluded higher concentrations of NDF in their high MS diets may have counteracted negative effects of a higher starch concentration and MS composition per se on methane yield compared with high GS diets. This observation is partly supported in this study where adding NDF to the diet increased methane yield from cows fed high MS, but not high GS.

\section{Methane Measurement Techniques to Detect Dietary Treatment Effects}

The GF system has capability to estimate methane emission from greater numbers of animals, is less restrictive to animal behavior for measurement of methane emission, and does not require extensive laboratory equipment or labor. In our study, although the magnitude of the difference in methane yield varied between techniques for dietary forage type (24\% lower in experiment 1 using GF and 8\% lower in experiment 2 using $\mathrm{RC}$ for MS vs. GS), overall the techniques were able to detect similar dietary treatment effects and overall methane emission from lactating dairy cows $(448 \mathrm{~g} / \mathrm{d}$ and $20.9 \mathrm{~g} / \mathrm{kg}$ of DMI for GF vs. 458 and 23.8 for RC, respectively). This was similar to Hammond et al. (2015a), who found that despite concordance analyses finding no agreement between GF and RC, overall the GF system provided an average (grand mean) estimate of methane emission by growing dairy cattle that was not different from RC measurements.

Both techniques detected a significant interaction between forage type and NDF treatment, and measured a lower methane yield from cows fed high MS compared with high GS diets. This is in contrast to Hammond et al. (2015a) who used 4 growing dairy cattle in a $4 \times$ 4 Latin square design and found GF unable to detect changes in methane emission due to treatment or animal effects that were detected using RC. In that study, cattle had GF access for only $7 \mathrm{~d}$ of each treatment period, and entered $\mathrm{RC}$ for $72 \mathrm{~h}$ at the end of the treatment period, whereas in the present study, a greater number of GF measurements was obtained daily from more animals over a longer period ( $3 \mathrm{wk})$ in an attempt to increase the sample size and better represent the daily pattern of methane emission.
Unlike experiment 2, which used RC and found methane production $(\mathrm{g} / \mathrm{d})$ to vary between dietary treatments, methane production estimated using GF was not significantly affected by dietary treatment for experiment 1. This difference between experiments could be due to several factors, including the animals themselves and their gut microbes, their level of intake, the timing of measurements, and other environmental factors. The difference in the results could also be due to differences in the timing of methane sampling measurements relative to diurnal patterns of methane production and feeding. Respiration chambers take a continuous measurement of methane over $24 \mathrm{~h}$, thus capturing varying methane emission patterns, whereas methane measurements using GF rely on animal visitation, which is mostly dictated by the behavior of the animal.

The reliance of a feed enticement to generate a measure of methane is a limitation of the GF technique, as observed with a varying diet composition within experiment 1 (wk 1 to 8 vs. wk 10 to 12) and compared with experiment 2. This is a concern in both pastoral grazing systems and animal nutrition studies where there is the possibility of excessive or variable contribution of attractant to the animals diet, even if restrictions are imposed (Waghorn et al., 2013; Dorich et al., 2015; Hammond et al., 2015a). Animals on a high GS diet visited the GF more regularly than animals on a high MS diet, and this influenced the overall composition and intakes of starch and NDF, despite the attempt to accommodate this in the TMR formulation. A similar observation was found in Hammond et al. (2015a) where more visits to the GF were made when heifers were grazing a multi-species sward compared with ryegrass and clover.

\section{CONCLUSIONS}

This study examined the effects of variations in forage proportions of MS and GS, with or without additional NDF concentration on feed intake, milk production and composition, and methane emission in lactating dairy cattle, and used GF as an alternative method to RC to measure dietary effects on methane emission. As hypothesized, cows fed high MS diets had a greater DMI, milk production, and lower methane yield $(\mathrm{g} / \mathrm{kg}$ of DMI), compared with cows fed high GS diets. Added NDF to both high MS and GS diets decreased DMI and milk yield, and increased methane yield for high MS but not high GS diets. Both the GF and RC methods detected similar dietary treatment effects on methane yield, although the magnitude of the difference varied between experiments (and techniques) for dietary treatments. Overall average methane production and yield 
were similar for the 2 experiments using different cows, experimental conditions, and measurement techniques.

\section{ACKNOWLEDGMENTS}

This study was funded by Defra, the Scottish Government, DARD, and the Welsh government as part of the UK's Agricultural GHG Research Platform project (www.ghgplatform.org.uk). Contributions from the technical staff of University of Reading's Centre for Dairy Research in the daily routine of experiments and care of cows, as well as assistance from C-Lock Inc., with regard to GreenFeed operation and use, is gratefully acknowledged.

\section{REFERENCES}

AOAC International. 2005. Official Method of Analysis. 18th ed. AOAC International, Gaithersburg, MD.

Beauchemin, K. A., M. Kreuzer, F. P. O'Mara, and T. A. McAllister 2008. Nutritional management for enteric methane abatement: A review. Aust. J. Exp. Agric. 48:21-27.

Brask, M., P. Lund, A. L. F. Hellwing, M. Poulsen, and M. R. Weisbjerg. 2013. Enteric methane production, digestibility and rumen fermentation in dairy cows fed different forages with and without rapeseed fat supplementation. Anim. Feed Sci. Technol. 184:67-69.

Brouwer, E. 1965. Report of sub-committee on constants and factors. Pages 441-443 in Energy Metabolism. K. L. Blaxter, ed. European Association for Animal Production publication no. 11. Academic Press, London, UK.

Cammell, S. B., D. E. Beever, K. V. Skelton, and M. C. Spooner. 1981. The construction of open-circuit calorimeters for measuring gaseous exchange and heat production in sheep and growing cattle. Lab. Pract. 30:115-119.

Cammell, S. B., D. J. Thomson, D. E. Beever, M. J. Haines, M. S. Dhanoa, and M. C. Spooner. 1986. The efficiency of energy utilization in growing cattle consuming fresh perennial ryegrass (Lolium perenne cv. Melle) or white clover (Trifolium repens cv. Blanca). Br. J. Nutr. 55:669-680

Dorich, C. D., R. K. Varner, A. B. D. Pereira, R. Martineau, K. J. Soder, and A. F. Brito. 2015. Short communication: Use of a portable, automated, open-circuit gas quantification system and the sulfur hexafluoride tracer technique for measuring enteric methane emissions in Holstein cows fed ad libitum or restricted. J. Dairy Sci. 98:2676-2681.

Gaillard, C., N. C. Friggens, M. Taghipoor, M. R. Weisbjerg, J. O. Lehmann, and J. Sehested. 2016. Effects of an individual weightadjusted feeding strategy in early lactation on milk production of Holstein cows during extended lactation. J. Dairy Sci. 99:22212236.

Gaines, W. L. 1928. The energy basis of measuring milk yield in dairy cows. University of Illinois Agric. Exp. Station Bull. 308.

Hammond, K. J., D. J. Humphries, L. A. Crompton, C. Green, and C. K. Reynolds. 2015a. Methane emissions from cattle: Estimates from short-term measurements using a GreenFeed system compared with measurements obtained using respiration chambers or sulphur hexafluoride tracer. Anim. Feed Sci. Technol. 203:41-52.

Hammond, K. J., D. J. Humphries, L. A. Crompton, P. Kirton, and C. K. Reynolds. 2015b. Effects of forage source and extruded linseed supplementation on methane emissions from growing dairy cattle of differing body weights. J. Dairy Sci. 98:8066-8077.

Hammond, K. J., D. J. Humphries, D. B. Westbury, A. Thompson, L. A. Crompton, P. Kirton, C. Green, and C. K. Reynolds. 2014. The inclusion of forage mixtures in the diet of growing dairy heifers: Impacts on digestion, energy utilisation, and methane emissions. Agric. Ecosyst. Environ. 197:88-95.
Hammond, K. J., G. C. Waghorn, and R. S. Hegarty. 2016. The GreenFeed system for measurement of enteric methane emissions from cattle. Anim. Prod. Sci. 56:181-189.

Herskin, M. S., R. Müller, L. Schrader, and J. Ladewig. 2003. A laser-based method to measure thermal nociception in dairy cows: Short-term repeatability and effects of power output and skin condition. J. Anim. Sci. 81:945-954.

Hristov, A. N., J. Oh, F. Giallongo, T. Frederick, H. Weeks, P. R. Zimmerman, R. A. Hristova, S. R. Zimmerman, and A. F. Branco. 2015. The use of an automated system (GreenFeed) to monitor enteric methane and carbon dioxide emissions from ruminant animals. J. Vis. Exp. 103:e52904. http://dx.doi.org/10.3791/52904.

Huhtanen, P., E. H. Cabezas-Garcia, S. Utsumi, and S. Zimmerman. 2015. Comparison of methods to determine methane emissions from dairy cows in farm conditions. J. Dairy Sci. 98:3394-3409.

IPCC. 2007. Climate change 2007: The Physical Science Basis. In Contribution of Working Group 1 to the Fourth Assessment Report of the Intergovernmental Panel on Climate Change. S. Solomon, D. Qin, M. Manning, Z. Chen, M. Marquis, K. Averyt, M. Tignor, and H. Miller, ed. Cambridge University Press, Cambridge, UK.

Janssen, P. H. 2010. Influence of hydrogen on rumen methane formation and fermentation balances through microbial growth kinetics and fermentation thermodynamics. Anim. Feed Sci. Technol. $160: 1-22$.

Kendall, C., C. Leonardi, P. C. Hoffman, and D. K. Combs. 2009. Intake and milk production of cows fed diets that differed in dietary neutral detergent fiber and neutral detergent fiber digestibility. J. Dairy Sci. 92:313-323.

Khan, N. A., P. Yu, M. Ali, J. W. Cone, and W. H. Hendriks. 2015 Nutritive value of maize silage in relation to dairy cow performance and milk quality. J. Sci. Food Agric. 95:238-252.

Kliem, K. E., R. Morgan, D. J. Humphries, K. J. Shingfield, and D. I. Givens. 2008. Effect of replacing grass silage with maize silage in the diet on bovine milk fatty acid composition. Animal $2: 1850-1858$.

Livingstone, K. M., D. J. Humphries, P. Kirton, K. E. Kliem, D. I. Givens, and C. K. Reynolds. 2015. Effects of forage type and extruded linseed supplementation on methane production and milk fatty acid composition of lactating dairy cows. J. Dairy Sci. 98:4000-4011.

Mc Court, A. R., T. Yan, and C. S. Mayne. 2007. Effect of forage type on methane production from dairy cows. Page 48 in Proc. Br. Soc. Anim. Sci., Southport, UK. Cambridge University Press, Cambridge, UK.

Mertens, D. R. 2002. Gravimetric determination of amylase-treated neutral detergent fiber in feeds with refluxing in beakers or crucibles: Collaborative study. J. AOAC Int. 85:1217-1240.

Mills, J. A., J. Dijkstra, A. Bannink, S. B. Cammell, E. Kebreab, and J. France. 2001. A mechanistic model of whole-tract digestion and methanogenesis in the lactating dairy cow: Model development, evaluation, and application. J. Anim. Sci. 79:1584-1597.

O'Mara, F. P., J. J. Fitzgerald, J. J. Murphy, and M. Rath. 1998. The effect on milk production of replacing grass silage with maize silage in the diet of dairy cows. Livest. Prod. Sci. 55:79-87.

Phipps, R. H., J. D. Sutton, and B. A. Jones. 1995. Forage mixtures for dairy cows: the effect on dry-matter intake and milk production of incorporating either fermented or urea-treated whole-crop wheat, brewers' grains, fodder beet or maize silage into diets based on grass silage. Anim. Sci. 61:491-496.

Phipps, R. H., R. F. Weller, R. J. Elliott, and J. D. Sutton. 1988. The effect of level and type of concentrate and type of conserved forage on dry matter intake and milk production of lactating dairy cows. J. Agric. Sci. 111:179-186.

Phipps, R. H., R. F. Weller, and A. J. Rook. 1992. Forage mixtures for dairy cows: The effect on dry matter intake and milk production of incorporating different proportions of maize silage into diets based on grass silages of differing energy value. J. Agric. Sci. 118:379-382.

Reynolds, C. K., S. B. Cammell, D. J. Humphries, D. E. Beever, J. D. Sutton, and J. R. Newbold. 2001. Effects of postrumen starch 
infusion on milk production and energy metabolism in dairy cows. J. Dairy Sci. 84:2250-2259.

Reynolds, C. K., L. A. Crompton, J. A. N. Mills, D. J. Humphries, P. Kirton, A. E. Relling, T. H. Misselbrook, D. R. Chadwick, and D. I. Givens. 2010. Effects of diet protein level and forage source on energy and nitrogen balance in methane and nitrogen excretion in lactating dairy cows. G. M. Crovetto, ed. Energy and Protein Metabolism and Nutrition Symposium, 127:736. Wageningen Academic Publishers, the Netherlands.

Reynolds, C. K., D. J. Humphries, P. Kirton, M. Kindermann, S. Duval, and W. Steinberg. 2014. Effects of 3-nitrooxypropanol on methane emission, digestion, and energy and nitrogen balance of lactating dairy cows. J. Dairy Sci. 97:3777-3789.

Robertson, J. B., and P. J. Van Soest. 1981. The detergent system of analysis and its application to human foods. Pages 123-158 in The Analysis of Dietary Fiber in Food. Vol. 3. W. James and O. Theander, ed. Marcel Dekker Inc., New York, NY.

Staerfl, S. M., J. O. Zeitz, M. Kreuzer, and C. R. Soliva. 2012. Methane conversion rate of bulls fattened on grass or maize silage as compared with the IPCC default values, and the long-term methane mitigation efficiency of adding acacia tannin, garlic, maca and lupine. Agric. Ecosyst. Environ. 148:111-120.

Thomas, C. 2007. Feed into milk: A new applied feeding system for dairy cows. Nottingham University Press, Nottingham, UK.

van Gastelen, S., E. C. Antunes-Fernandes, K. A. Hettinga, G. Klop, S. J. J. Alferink, W. H. Hendriks, and J. Dijkstra. 2015. Enteric methane production, rumen volatile fatty acid concentrations, and milk fatty acid composition in lactating Holstein-Friesian cows fed grass silage- or corn silage-based diets. J. Dairy Sci. 98:1915-1927.

Waghorn, G. C. E. J. Garnett, C. S. Pinares-Patino, and S. Zimmerman. 2013. Implementation of GreenFeed in a dairy herd grazing pasture. Advances in Animal Biosciences, Proceedings of the 5th Greenhouse Gases and Animal Agriculture Conference (GGAA2013), Dublin, Ireland, 4:436.

Zimmerman, P. R., and R. S. Zimmerman, inventors; C-Lock Inc., assignee. 2012. Method and system for monitoring and reducing ruminant methane production. United States Patent number US2009028806 A1. 